\title{
Collusion in a One-Period Insurance Market with Adverse Selection
}

\author{
Alexander Alegría* and Manuel Willington ${ }^{\ddagger}$
}

March, 2008

\begin{abstract}
We show how collusive outcomes may occur in equilibrium in a one-period competitive insurance market characterized by adverse selection. We build on the Inderst and Wambach (2001) model -this shows that the Rothschild and Stiglitz separating equilibrium always exists when there are capacity constraints- and we assume that insurees must pay a minimum premium, which is a common feature in many health systems. In this setup we show that there is a range of equilibria, from the zero profit one in which low-risks implicitly subsidize high risks, to one where firms obtain profits with both types of consumers. Moreover, we show that rents only partially dissipate if we assume free entry.

Along these equilibria, high risks always obtain full insurance while the low risks coverage decreases as the firms' profits increase. Recently the Chilean antitrust authority (Fiscalía Nacional Económica) accused five of the largest private health insurers of collusion after they had reduced the coverage offered to their customers and as a result significantly raised their profits. Our model is consistent with this accusation.

KEYWORDS: adverse selection, collusion, insurance, capacity constraints.

JEL NuMBers: I11, I18, L41

Correspondent: Manuel Willington, Universidad Alberto Hurtado, Erasmo Escala 1835, Santiago, Chile.

Phone: 56-2-6920265. Fax: 56-2-6920303. Email: mwilling@uahurtado.cl
\end{abstract}

*ILADES - Georgetown University, Santiago, Chile.

$\dagger$ Universidad Alberto Hurtado, Santiago, Chile.

${ }^{\ddagger}$ Georgetown University, DC, USA. 


\section{Introduction}

The equilibrium that may exist in an adverse selection insurance model was characterized in the Rothschild and Stiglitz (1976) paper (henceforth R\&S). In that work it was shown that the only possible equilibrium is a separating one - where low risks are only partially insured and high risks receive full coverage -, and that it may not exist when the proportion of low risks is sufficiently large. After this publication, a myriad of papers followed, with some of them addressing the issues of the (potential) non-existence of separating equilibria (e.g., Dasgupta and Maskin, 1986; Hellwig, 1987 and 1988; Asheim and Nilssen, 1996; Inderst and Wambach, 2001) and also the non-existence of pooling equilibria (e.g., Allard, Cresta and Rochet, 1997; Newhouse, 1996).

Our starting point in this work is the Inderst and Wambach model (I\&W from now on). This introduced capacity constraints to the R\&S model and showed that the separating equilibrium always exists (under some mild additional assumptions). The intuition leading to this result is straightforward. The separating equilibrium failed to exist in $R \& S$ when it could be destabilized by a Pareto superior pooling contract that would be preferred -and bought- by all consumers. However, under capacity constraints, the pooling contract would be bought by only a fraction of consumers; and these would be high risk consumers as they have more to win and are therefore ready to face, with some probability, some positive search costs.

We add to this model a feature which is common to many health systems: consumers are obliged to get health insurance and pay some minimum premium. We fully characterize the set of subgame-perfect Nash equilibria, assuming that the minimum premium constraint is binding for low-risk consumers (i.e., the R\&S separating equilibria is ruled out by this constraint). Our main result is that there is a continuum of equilibria ranging from a competitive one -with zero profits for all firms- to more collusive outcomes. As firms' profits increase, the coverage of low risks decreases (their premiums remain at the lowest possible) and the premium for high risks increases (and they remain fully covered). Moreover, free entry reduces the scope of equilibria, but rents never dissipate completely. 
Our results are consistent with a recent trend observed in the Chilean health insurance market, where within a year five of the largest companies reduced their coverage and were subsequently accused of anti-competitive behavior by the national antitrust agency (Fiscalía Nacional Económica). However, in the trial, the judges did not find the evidence conclusive and therefore pronounced a not guilty verdict.

The rest of the paper is organized as follows. In Section 2 we present our model and briefly illustrate $R \& S$ and $I \& W$ results. In Section 3 we provide proofs for our results. Conclusions are given in Section 4.

\section{The model}

Our model is very similar to the one of I\&W, with an additional feature: we assume all consumers are forced to buy insurance and to pay a minimum premium. We now describe the model and introduce our notation.

\section{Consumers and Insurance Contracts}

There are $N$ consumers in the economy whose expected utility function when they buy no insurance is

$$
\pi_{x} u(W-D)+\left(1-\pi_{x}\right) u(W),
$$

where $W$ is the individuals' initial wealth, $u(\cdot)$ is an strictly increasing and strictly concave function, and the subindex $x$ denotes the individual's type $\{H, L\}$, which determines the probability $\pi_{x}$ that the individual suffers the loss $D$. We assume $0<\pi_{L}<\pi_{H}<1$. We further assume that each individual has a probability $\gamma \in(0,1)$ of being type $H$.

An insurance contract in this setup is a pair $(\alpha, \beta)$, where $\alpha$ is the premium insurees pay (in all events) and $\beta$ is the gross indemnity. Therefore, the expected utility of a type- $x$ insured individual is

$$
U_{x}(\alpha, \beta) \equiv \pi_{x} u(W-D-\alpha+\beta)+\left(1-\pi_{x}\right) u(W-\alpha) .
$$




\section{Firms}

We assume there are $F$ risk neutral firms that by offering a contract $(\alpha, \beta)$ to a type $x$ consumer obtain an expected profit of $\alpha-\beta \pi_{x}$. With no loss of generality, we assume that each firm offers a menu of two incentive-compatible contracts denoted by $\left\{\left(\alpha_{L}, \beta_{L}\right),\left(\alpha_{H}, \beta_{H}\right)\right\}$. Therefore, these satisfy

$$
\begin{aligned}
\pi_{L} u\left(W-D-\alpha_{L}+\beta_{L}\right)+\left(1-\pi_{L}\right) u\left(W-\alpha_{L}\right) & \geq \\
& \pi_{L} u\left(W-S-\alpha_{H}+\beta_{H}\right)+\left(1-\pi_{L}\right) u\left(W-\alpha_{H}\right)
\end{aligned}
$$

and

$$
\begin{aligned}
\pi_{H} u\left(W-D-\alpha_{H}+\beta_{H}\right)+\left(1-\pi_{H}\right) & u\left(W-\alpha_{H}\right) \geq \\
& \pi_{H} u\left(W-S-\alpha_{L}+\beta_{L}\right)+\left(1-\pi_{H}\right) u\left(W-\alpha_{L}\right) .
\end{aligned}
$$

For simplicity we assume all firms are identical and, as in I\&W, that they have a maximum capacity constraint $k$ (logically, $k<N$ ). Furthermore, we assume that no firm is indispensable to serve all the market, therefore $(F-1) k \geq N$, and $k \geq\left\lfloor\frac{N}{F-1}\right\rfloor+F-1$. $^{1}$

\section{Timing of the Game}

The timing of the game is as follows: At 0, nature reveals to each individual his type, AND at 1 firms offer menu of contracts (without knowing the type of each particular individual). Then at 2, consumers choose the firm and the contract that they will sign. If no firm faces a larger demand than its own capacity, the game ends.

However, off the equilibrium path, consumers could be rationed if many of them choose the same firm. We assume that in such a case all individuals face the same risk of being rationed: let $n^{j}$ be the number of consumers who go to firm $j$, then the probability of being rationed is $\max \left\{0, \frac{n^{j}-k}{k}\right\}$. Rationed consumers will have the option of seeking insurance in a different firm at a cost $c>0$ or remaining uninsured; which is equivalent to obtaining the

\footnotetext{
${ }^{1}\lfloor x\rfloor$ is the largest integer smaller than or equal to $x$. This assumption is made just to simplify the
} description of the symmetric equilibrium we present in Proposition 1 (obviously the assumption implies that $(F-1) k \geq N$ whenever $F \geq 2)$. 
contract $(\underline{\alpha}, 0)$ given our assumption that getting insurance is compulsory. ${ }^{2}$ Potentially, a consumer could be rationed many times.

The precise timing of the game is as follows:

\begin{tabular}{cccc} 
Nature & Each firm & Individuals & Rationed \\
chooses $\{h, l\}$ & offers a menu & choose firm & consumers seek \\
for each person & of contracts & and contract & new contract \\
$\downarrow$ & $\downarrow$ & $\downarrow$ & $\downarrow$ \\
0 & 1 & 2 & $2 \ldots$ \\
\hline
\end{tabular}

\section{Rothschild and Stiglitz Separating Equilibrium}

Figure 2.1 illustrates the separating equilibrium when the proportion of low-risk consumers is not "too large": point $E$ illustrates the situation when consumers buy no insurance, the straight line $\pi_{L}=0$ represents all allocations type- $l$ consumers can reach buying insurance at an actuarially fair premium. Along this line, firms selling insurance only to type- $l$ consumers obtain zero profits. The line $\pi_{H}=0$ is the analogous for type- $h$ consumers, and $\pi^{\prime}=0$ is the relevant one when all consumers (type $h$ and $l$ ) are pooled in the same contract.

The pair $R S_{H}$ and $R S_{L}$ are the equilibrium allocations for each type: consumers self-select their respective contracts - that we will denote by $\left(\alpha_{L}^{R S}, \beta_{L}^{R S}\right)$ and $\left(\alpha_{H}^{R S}, \beta_{H}^{R S}\right)-$, firms obtain zero profits, and no firm can deviate and offer an alternative contract and make strictly positive profits.

The non-existence problem is illustrated in Figure 2.2: given the large proportion of low risks (note that $\pi^{\prime}$ is now closer to $\pi_{L}$ ), if all firms offer contracts such that $R S_{H}$ and $R S_{L}$ are reached, then one firm could deviate offering a contract in the dotted region. Such a contract would be attractive to all consumers and produce strictly positive profits (as it is below $\left.\pi^{\prime}\right)$.

Is it then possible to have a pooling equilibrium? No, as if there is one that yields an allocation $P$ on the $\pi^{\prime}=0$ line, then an alternative contract yielding an allocation $P^{\prime}$ could

\footnotetext{
${ }^{2}$ We will present an extension of the model where the "default option" is a public insurer that offers a given level of coverage rather than no coverage at all. Qualitatively the results will not change.
} 


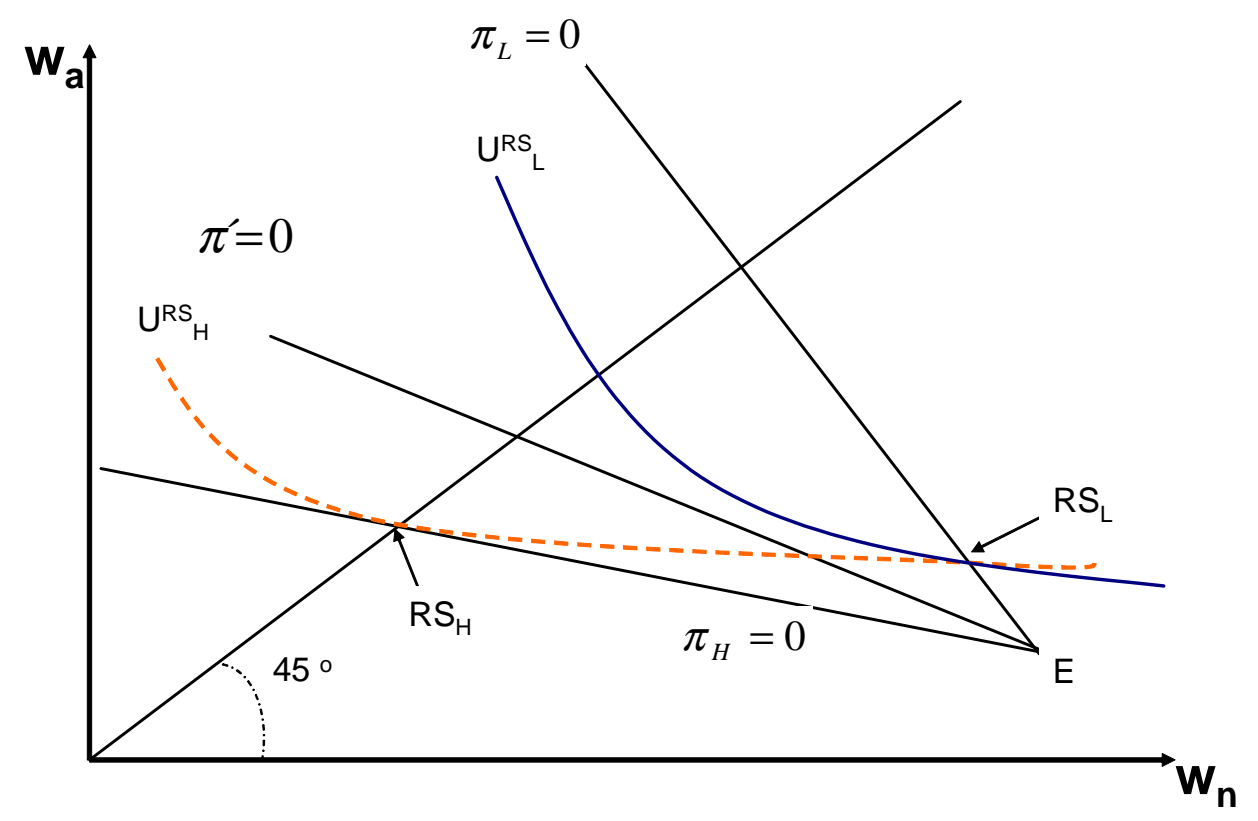

Figure 2.1: Rothschild and Stiglitz Separating Equilibrium

be offered, and that contract would be chosen only by low-risks and would therefore produce strictly positive profits.

\section{Inderst and Wambach Solution}

I\&W solve the non-existence problem discussed above by assuming that firms have capacity constraints and that rationed consumers must face a "search cost" to obtain insurance. We shall not discuss their result formally since the proof we will present for our results closely follows I\&W's logic. However, the intuition (in the problematic case depicted in Figure 2.2) is the following: if a firm now offers a contract in the dotted region, then all consumers would certainly prefer such a contract. Then, given that firms are capacity constrained there will be a positive probability of being rationed (and therefore facing the search cost). Since high-risk consumers have more to win by getting the new contract (this is a consequence of the well known single crossing property that characterizes these models), in equilibrium (of the subgame) only they would go to the deviating firm, which as a result would then make losses (as the dotted region is above the $\pi_{H}=0$ line). ${ }^{3}$

\footnotetext{
${ }^{3}$ Some additional assumptions are required to construct this equilibrium: the search cost can not be
} 


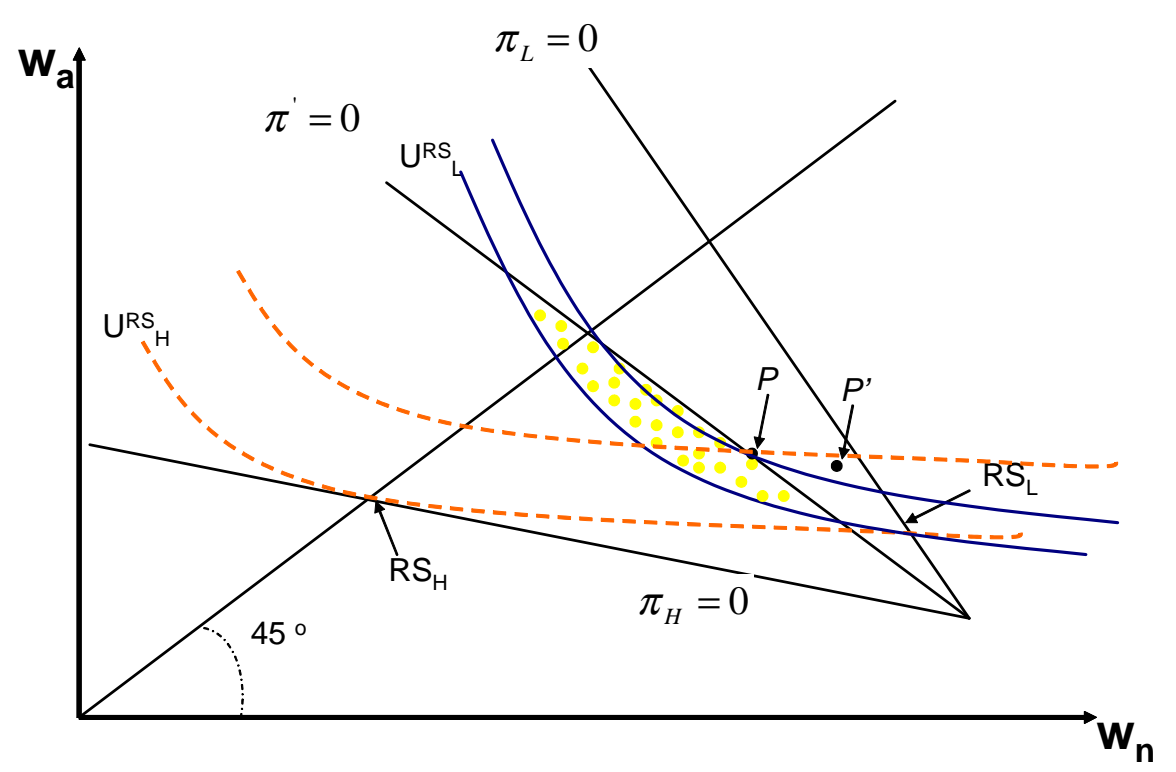

Figure 2.2: Non-existence of Equilibrium in R\&S Model

\section{Results}

For our minimum premium assumption to have any bite it must be binding in equilibrium. We will assume that this is the case, therefore

$$
\underline{\alpha}>\alpha_{L}^{R S} .
$$

Moreover, we will assume that the minimum premium constraint is never binding for high risks. This assumption is illustrated in Figure 3.1, where we show the continuum of equilibria that exists when we impose this constraint.

The equilibria range from the pair of contracts $\left(\underline{\alpha}, \beta_{L}^{Z}\right)$ and $\left(\alpha_{H}^{Z}, D\right)$ that yield the depicted allocations $\left(Z_{L}, Z_{H}\right)$ to the contracts $\left(\underline{\alpha}, \beta_{L}^{A}\right)$ and $\left(\alpha_{H}^{A}, D\right)$ that yield the allocations $\left(A_{L}, A_{H}\right)$. The pair $\left(\underline{\alpha}, \beta_{L}^{Z}\right)$ and $\left(\alpha_{H}^{Z}, D\right)$ is such that firms make zero profits when they get avoided, it should also not be excessively large, with the capacity of each firm being relatively small compared to the size of the market. We will adapt these assumptions to our model and then state them formally in the next section. 
a fraction $\gamma$ of low risks and $1-\gamma$ of high risks, with the incentive compatibility constraint $(\underline{I C})$ being satisfied as an equality.

At the other extreme, the pair $\left(\underline{\alpha}, \beta_{L}^{A}\right)$ and $\left(\alpha_{H}^{A}, D\right)$ is such that $(\underline{I C})$ is again satisfied as an equality, with no firm being able to make larger profits by filling its capacity with high risks that buy the contract $\left(\alpha_{H}^{A}, D\right) .{ }^{4}$ Between these extrema, any pair such that $(\underline{I C})$ holds as an equality, high risks receive full insurance, and low risks pay the minimum premium can be sustained as a subgame perfect Nash equilibrium of the original game.

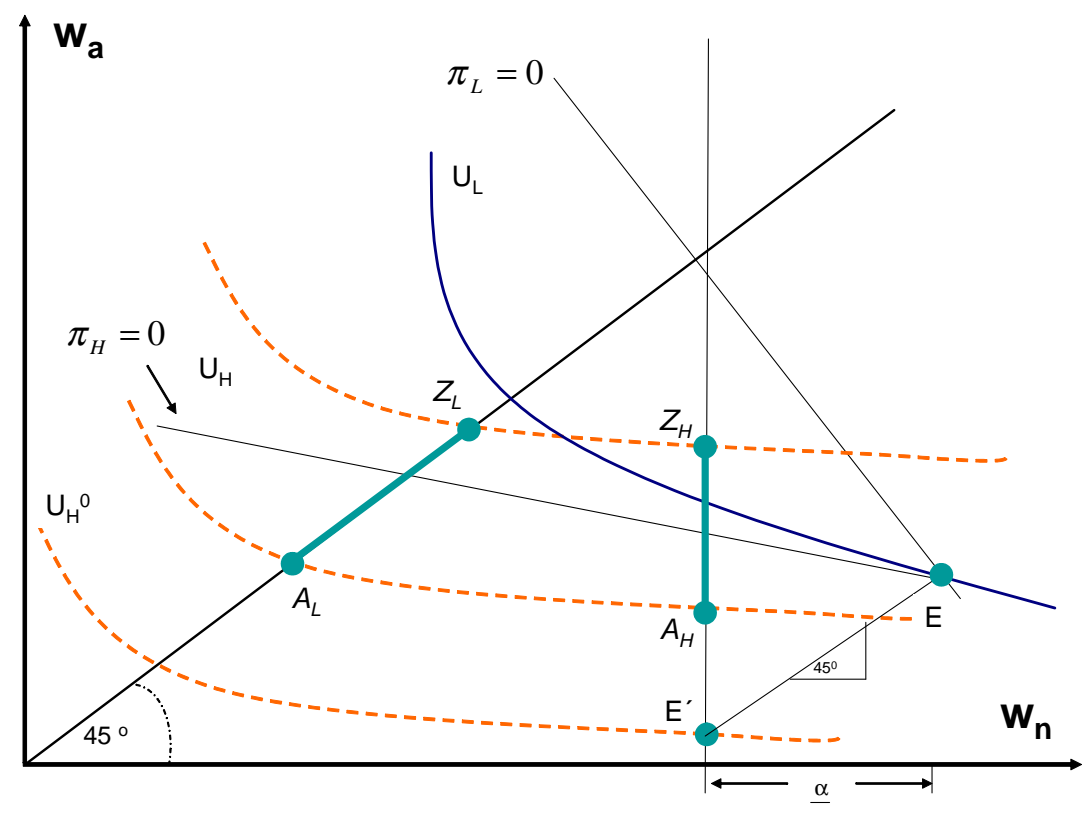

Figure 3.1: Continuum of Equilibrium with Minimum Premium Constraint

To formalize this result we need to make two additional assumptions that are related to the firms' maximum capacity and the search costs. These assumptions are similar to those in I\&W, differing only because the default option for consumers in I\&W is not to buy insurance at all whereas in our model they must always pay the minimum premium $\underline{\alpha}$.

The first assumption sets an upper limit to the search cost $c$, which must be such that the rationed customer prefers to visit another firm if he knows he will be able to get his

\footnotetext{
${ }^{4}$ See the Appendix for a formal proof of the existence of such a $\beta_{L}^{A}$.
} 
(separating) equilibrium contract rather than remaining uninsured (and paying $\underline{\alpha}){ }^{5}$

$$
U_{H}\left(\alpha_{H}^{A}, D\right)-c>U_{H}(\underline{\alpha}, 0)
$$

Then, the second assumption sets a lower limit to $c$, related also to the firms' maximum capacity:

$$
\left(1-\rho^{M}\right) U_{H}\left(\alpha^{*}, \beta^{*}\right)+\rho^{M}\left[U_{H}\left(\alpha_{H}^{A}, D\right)-c\right]<U_{H}\left(\alpha_{H}^{A}, D\right),
$$

where $\rho^{M}$ is defined as the expected rationing probability a consumer would face if all type $H$ individuals go to same firm and he also chooses to go to that particular firm. ${ }^{6} U_{H}\left(\alpha^{*}, \beta^{*}\right)$ is the utility level a type $H$ individual could get if he is offered his most preferred contract in the set $\left\{(\alpha, \beta):\left(\alpha=\pi_{l} \beta\right) \wedge(\alpha \geq \underline{\alpha})\right\}$ (i.e., the most preferred contract with a low-type fair premium that also satisfies the minimum premium constraint).

Note that this assumption is never satisfied if $c=0$. However, it is always satisfied when, given the maximum capacity $k$, the number of individuals in the economy $N$ and the number of firms $J$ are large enough ( $\rho^{M}$ tends to one in such a case).

We can now formally state our result

Proposition 1. Assuming that $(A 0),(A 1)$, and $(A 2)$ hold. There is a continuum of symmetric subgame perfect Nash equilibria where no individual is rationed and all firms offer the menu $\left\{\left(\underline{\alpha}, \beta_{L}\right),\left(\alpha_{H}, D\right)\right\}$ that satisfies the following conditions:

1.

$$
U_{L}\left(\alpha_{h}, D\right)=U_{L}\left(\underline{\alpha}, \beta_{L}\right)
$$

2.

$$
\gamma\left(\alpha_{H}-\pi_{H} D\right)+(1-\gamma)\left(\underline{\alpha}-\pi_{L} \beta_{L}\right) \geq 0
$$

${ }^{5}$ If $c$ were too large, then $h$-types rather than $l$-types would be unwilling to risk being rationed, as they would face a larger cost by remaining uninsured. A deviating firm could then attract only low-risks.

${ }^{6}$ Formally, $\rho^{M}=\sum_{m=0}^{N-1} \operatorname{Pr}\left(N_{H}=m\right) \max \left\{0, \frac{m-k}{k}\right\}$ where $\operatorname{Pr}\left(N_{H}=m\right)=\left(\begin{array}{c}N-1 \\ m\end{array}\right) \gamma^{m}(1-\gamma)^{N-1-m}$ is the probability that there are exactly $m$ high-risk individuals in the population. 
3.

$$
\frac{N}{J}\left[\gamma\left(\alpha_{H}-\pi_{H} D\right)+(1-\gamma)\left(\underline{\alpha}-\pi_{L} \beta_{L}\right)\right] \geq k\left(\alpha_{H}-\pi_{H} D\right)
$$

The formal proof is relegated to the Appendix.

What is the intuition for the proof? Take any of the proposed equilibrium in Proposition 1. A firm could deviate from the prescribed equilibria in three qualitatively different ways (recall $\underline{\alpha}$ is a minimum premium so no deviation can lower $\alpha_{l}$ ). First, it could choose a menu such that both types are worse off, but that would never be optimal because the firm would be left with no clients (recall we assumed that no firm is indispensable).

Second, it could deviate with a menu such that both types of consumers are better off. The intuition why this deviation will not pay is more subtle: by the single crossing property that our expected utility functions satisfy, any incentive compatible deviation menu will necessarily do more for type $H$ consumers than for the $L$-types. Then, type $H$ customers will be more willing to risk being rationed, and in any continuation equilibrium the number of high risk individuals willing to go in the first place to the deviating firm is such that $L$-type customers prefer to get the original contract with probability one. Therefore, as the deviating firm will attract only type $H$ customers, the deviation will not pay.

Finally, it could choose a menu such that only type $H$ consumers are better-off, but then it will have only type $H$ customers and condition 3 in our proposition guarantees that this is not a profitable deviation. ${ }^{7}$

Obviously, the second condition of the proposition guarantees that firms prefer to offer the prescribed contract rather than not offering any contract at all.

\section{Free Entry}

Our previous proposition characterized the set of equilibria assuming that the number of firms was given. Since in (almost) all the equilibria firms obtain a strictly positive profit,

${ }^{7}$ This is not obvious if the proposed deviation menu is such that type $l$ consumers are as well as with the contract offered by other firms. But, since the deviating firm is offering a better contract for $h$-type consumers, in any continuation equilibria there must be congestion, so the $l$ type will strictly prefer to choose a different firm. 
it is worth analyzing the potential effect of entry in the equilibrium set. It turns out that entry shrinks the equilibrium set (and in this case the aggregated profits that firms obtain), but it never reduces it to the zero profit equilibrium $\left(z_{l}, z_{h}\right)$. Corollary 1 characterizes the set of equilibria when there are infinitely many potential entrants.

Our previous proposition characterized the set of equilibria assuming the number of firms was given. Since in (almost) all the equilibria firms obtain a strictly positive profit, it is worth analyzing the potential effect of entry in the equilibrium set. It turns out that entry shrinks the equilibrium set (and in that case the aggregated profits firms obtain), but will never reduce it to the zero profit equilibrium $\left(z_{l}, z_{h}\right)$. Corollary 1 characterizes the set of equilibria when there infinitely many potential entrants.

Corollary 1. Assuming $(A 0),(A 1)$, and $(A 2)$ hold. As the number of firms tends to infinity, there is a continuum of symmetric subgame perfect Nash equilibria where no individual is rationed and all firms offer the menu $\left\{\left(\underline{\alpha}, \beta_{L}\right),\left(\alpha_{H}, D\right)\right\}$ that satisfies the following conditions:

1.

$$
U_{L}\left(\alpha_{h}, D\right)=U_{L}\left(\underline{\alpha}, \beta_{L}\right)
$$

2 .

$$
\gamma\left(\alpha_{H}-\pi_{H} D\right)+(1-\gamma)\left(\underline{\alpha}-\pi_{L} \beta_{L}\right) \geq 0
$$

3.

$$
\pi_{H} D \geq \alpha_{H}
$$

The formal proof is omitted as it is straightforward from Proposition 1. The only difference between the two equilibrium sets is given by condition 3. As the number of firms tends to infinity, the profits for each of them at any symmetric equilibrium approach zero. However, if all firms were offering contracts that yielded positive profits for both high and low risks, then any firm could "specialize" in high-risk customers, fill its capacity and make larger profits! Therefore, the set of equilibria is restricted to contracts which yield non-positive profits with high-risk individuals. Figure 3.2 illustrates this result. 


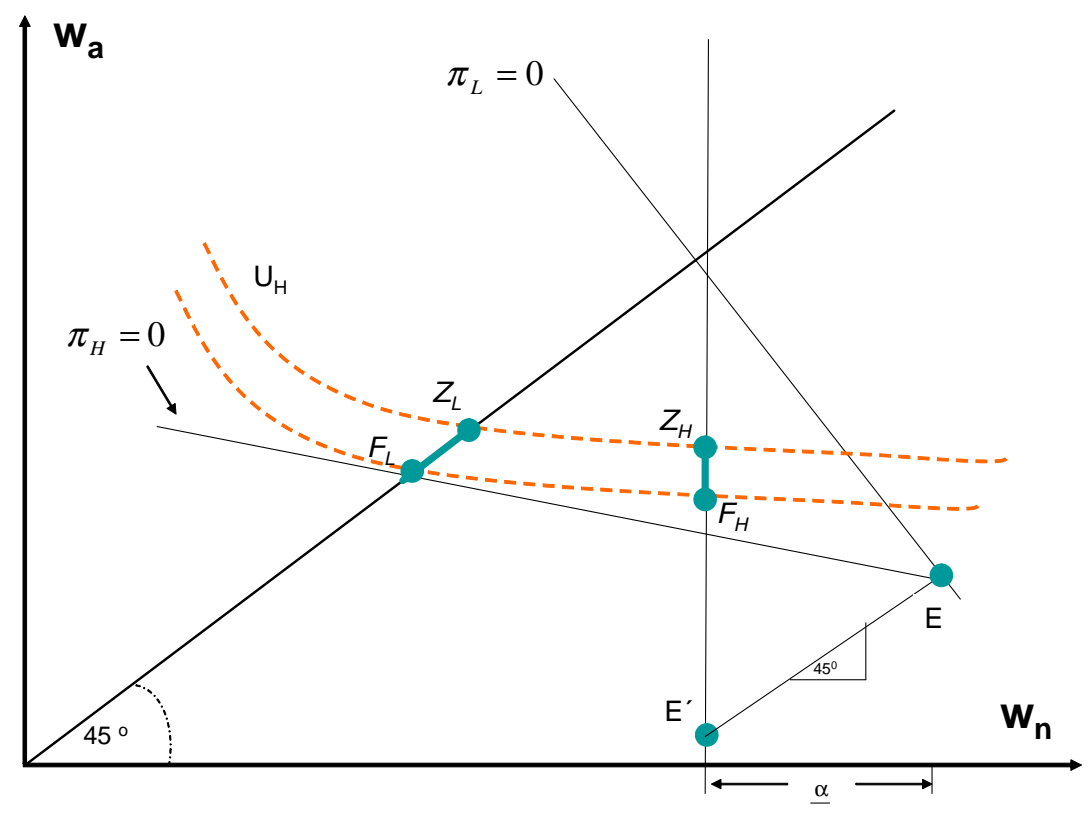

Figure 3.2: Equilibrium Set with Free Entry

\section{The Role of a Public Insurer}

In many countries, the private health insurance system coexists with a public one, with individuals having the option of subscribing to one or the other. ${ }^{8}$ A public insurer could be easily fitted into our model, assuming that it offers a single insurance contract $(\underline{\alpha}, \underline{\beta})$. This would then affect the default option that consumers have, and this may also affect the equilibrium set: if $\underline{\beta}$ is less than the coverage offered to low risks in the allocation $A_{L}$ (see Figure 3.1), then the equilibrium set will not be affected. On the other hand, if $\beta$ is larger than the coverage associated to $A_{L}$, then the equilibrium set will obviously be reduced.

\footnotetext{
${ }^{8}$ This is the case in Chile, where salary workers must contribute at least $7 \%$ of their income to health insurance, and they choose weather to contribute to the public insurer or to a private one. See Fischer and Serra (1996) for a comprehensive analysis of the Chilean health insurance system.
} 


\section{Conclusions}

We have presented a model that considers several characteristics of many health insurance markets: the adverse selection problem that firms face, mandatory insurance and minimum premium, and also as a straightforward extension the presence of a public insurer. We have built on the model of Inderst and Wambach (2001), which by assuming capacity constraints for insurers and search costs for insurees, solves the (potential) problem of non-existence of equilibrium in the R\&S model.

We have added to this model a minimum premium constraint (with mandatory insurance), and have shown that for most equilibria firms obtain positive profits, even if there is free entry.

The intuition why such a collusive equilibrium can be sustained (even in a one-period game) is as follows: first of all, because of the minimum premium constraint, firms cannot attempt to attract low risks by reducing their coverage and premium. Price competition is therefore limited. Instead, in order to attract low risks they must increase coverage (and possibly the premium as well), being aware that high risks will be also attracted. This strategy would pay (just as in the R\&S model the separating equilibria could be destabilized by a contract that attracts both types) if they could attract enough low risks, but the combination of the capacity constraint and the adverse selection problem determines that only high risks would show up to the deviating firm!

What determines the maximum level of profits that can be sustained in equilibrium? In the basic model it is the potential profit that a firm could make by deviating from the collusive equilibrium and offering a contract only for high risks, which would allow the deviating firm to fill its capacity. Logically, the larger the spare capacity that firms have in equilibrium, the larger the profits from deviating will be, and the smaller the aggregated profits that can be sustained in equilibrium. In the case we have a public insurance, it could obviously restrict the equilibria set simply by offering an insurance plan better than the worst that could otherwise be offered in equilibrium. 


\section{A. Appendix}

Proof of Proposition 1. By defining an ordered set of firms $\mathbf{F}=\{1,2, \ldots, F\}$ and individuals $\mathbf{N}=\{1,2, \ldots, N\}$, a symmetric equilibrium can be constructed which is characterized by:

1. In equilibrium, all firms offer the same menu of contracts that satisfy the established conditions 1 . to 3 ..

2. In equilibrium, the first $\left\lfloor\frac{N}{F}\right\rfloor$ individuals visit firm 1 , the second $\left\lfloor\frac{N}{F}\right\rfloor$ individuals visit firm 2, etc. Each of the last $N-F\left\lfloor\frac{N}{F}\right\rfloor$ individuals follows a mixed strategy choosing each firm with a probability of $\frac{1}{F}$.

Naturally, individuals have no incentives to deviate since all firms offer the same menu of contracts and in the proposed equilibrium there is no rationing.

Suppose now that a firm deviates (with no loss of generality, the deviating menu must be incentive compatible. For simplicity we assume firm 1 deviates):

3. Offering a menu such that high risks are better off and low-risks are worse off could be profitable if the prospect of filling its capacity with high risks were better than the equilibrium payoff. However, condition 3. guarantees that this is not the case.

4. Offering a menu such that both types are worse off would give the deviating firm a payoff of zero, since $(F-1) k \geq N$.

5. For the case of a menu such that both types are better off (and the contract designed for low risks is such that $\alpha \leq \pi_{l} \beta$ ), we construct the following continuation equilibrium in which only high risks choose to visit the deviating firm with positive probability:

1. All low risks among the first $\left\lfloor\frac{N}{F-1}\right\rfloor$ visit firm 2, all low risks among the second $\left\lfloor\frac{N}{F-1}\right\rfloor$ visit firm 3, etc.

2. All high risks among the first $\left\lfloor\frac{N}{F-1}\right\rfloor$ visit firm 2 with probability $\phi$ and firm 1 with probability $1-\phi$, all low risks among the second $\left\lfloor\frac{N}{F-1}\right\rfloor$ visit firm 3 with probability $\phi$ and firm 1 with probability $1-\phi$, etc. 
3. Note that if individuals behave according to $a$. and $b$. rationing can occur only in the deviating firm. For those rationed, we specify that they go to their corresponding firms in the next period and get their equilibrium contract.

4. Let $U_{h}^{E}$ be the equilibrium utility for an $h$-type that gets his equilibrium contract and $U_{h}^{D}$ if he gets the contract offered by the deviating firm. For types $h$ to play the specified mixed strategy, the probability $\phi$ must satisfy the following condition:

$$
\rho(\phi)\left(U_{h}^{E}-c\right)+(1-\rho(\phi)) U_{h}^{D}=U_{h}^{E}
$$

where $\rho(\phi)$ is the expected rationing probability when all $h$-types mix with probability $\phi$.

The existence of such a $\phi$ (potentially different for different deviations) is guaranteed by assumption A.2: note that $\rho(1)=\rho^{M}$ and $U_{H}\left(\alpha^{*}, \beta^{*}\right) \geq U_{h}^{D}$, therefore

$$
\rho(1)\left(U_{h}^{E}-c\right)+(1-\rho(1)) U_{h}^{D}<U_{h}^{E}
$$

and, since $\rho(0)=0$,

$$
\rho(0)\left(U_{h}^{E}-c\right)+(1-\rho(0)) U_{h}^{D}>U_{h}^{E}
$$

by continuity there must exist a $\phi$ such that the equality holds.

Therefore, since only high types would visit the deviating firm -and given Condition 3. was assumed- the deviating firm would be worse off.

Proof of the Existence of $\beta_{L}^{A}:$. All we need to show is that there is a $\beta_{L}$ such that

$$
\frac{N}{F}\left[\gamma\left(\alpha_{H}-\pi_{H} D\right)+(1-\gamma)\left(\underline{\alpha}-\pi_{L} \beta_{L}\right)\right]<k\left(\alpha_{H}-\pi_{H} D\right)
$$

where $\alpha_{H}$ is such that $\left(\alpha_{H}, D\right)$ and $\left(\underline{\alpha}, \beta_{L}\right)$ satisfy the incentive compatibility constraint for high types as an equality. Since

$$
\frac{N}{F}\left[\gamma(0)+(1-\gamma)\left(\underline{\alpha}-\pi_{L} \beta_{L}\right)\right]>k(0)
$$


where $\beta_{L}$ is such that $\left(\pi_{H} D, D\right)$ and $\left(\underline{\alpha}, \beta_{L}\right)$ satisfy the incentive compatibility constraint for high types as an equality, by continuity there must exist a pair of incentive compatible contracts such that both sides are equal.

To show there is a $\beta_{L}$ such that the first inequality holds, notice that $(*)$ can be rewritten as

$$
\left(k-\frac{N}{F} \gamma\right)\left(\alpha_{H}-\pi_{H} D\right)>\frac{N}{F}(1-\gamma)\left(\underline{\alpha}-\pi_{L} \beta_{L}\right)
$$

and since

$$
\alpha_{H}-\pi_{H} D>\underline{\alpha}-\pi_{H} \beta_{L},
$$

it is sufficient to show that there is a $\beta_{L}$ such that

$$
\left(k-\frac{N}{F} \gamma\right)\left(\underline{\alpha}-\pi_{H} \beta_{L}\right)>\frac{N}{F}(1-\gamma)\left(\underline{\alpha}-\pi_{L} \beta_{L}\right),
$$

which must be true since $\pi_{H}>\pi_{L}$. 


\section{References}

Allard, Cresta and Rochet (1997): "Pooling and Separating Equilibria in Insurance Markets with Adverse Selection and Distribution Costs", The Geneva Papers on Risk and Insurance Theory, 22: 103-120.

Asheim, Geir and Tore Nielssen (1996): "Non-discriminating Renegotiation in a Competitive Insurance Market", European Economic Review, Vol. 40, № 10, (December), pp. $1717-1736$.

Dasgupta, Partha and Eric Maskin (1986): "The Existence of Equilibrium in Discontinuous Economic Games, II: Applications", Review of economic Studies, Vol. 53, N 1 , (January), pp. 27-41.

Fischer R. and P. Serra (1996): "Análisis Económico del Sistema de Seguros de Salud en Chile", Revista de Análisis Económico, Vol. 11, No 2, (November) pp.187-217.

Hellwig, Martin (1987): "Some Recent Developments in Theory of Competition in Markets with Adverse Selection", European Economic Review, Vol. 31, № 1, (October), pp. 319-325.

Hellwig, Martin (1988): "A Note on the Specification of Interfirm Communication in Insurance Markets with Adverse Selection", Journal of Economic Theory, Vol. 46, N 1 , (October), pp. 154-163.

Inderst, Roman and Achim Wambach (2001): "Competitive Insurance Markets under Adverse Selection and Capacity Constraints", European Economic Review, Vol. 45, N 10, pp.1981-1992.

Newhouse, J. (1996): "Reimbursing Health Plans and Health Providers: Efficiency in Production Versus Selection," Journal of Economic Literature, 34 (Sept.), 1236-1263.

Rothschild, Michael and Joseph Stiglitz (1976): "Equilibrium in Competitive Insurance Markets: An Essay on the Economics of Imperfect Information", Quarterly Journal of 
Economics, Vol 90, ํ4, pp. 629-649. 